\title{
CORRIGENDUM
}

\section{GSK-3 $\beta$ inhibition reverses axonal transport defects and behavioural phenotypes in Drosophila}

A Mudher, D Shepherd, TA Newman, P Mildren, JP Jukes, A Squire, A Mears, JA Drummond, S Berg, D MacKay, AA Asuni, R Bhat and S Lovestone

Molecular Psychiatry (2004) 9, 812. doi:10.1038/sj.mp.4001540

Correction to: Molecular Psychiatry (2004) 9, 522-530, doi: 10.1038/sj.mp. 4001483

Following publication of the above paper, the author has identified an error with the names of the authors attributed. The correct author names are above. 